DOI: 10.20535/2077-7264.1(71).2021.232196

() О. Б. Книш, канд. техн. наук, доц., Українська академія друкарства, Львів, Україна

\title{
РОЗРОБЛЕННЯ ПРИСТРОЮ ДЛЯ ЗРІЗУВАННЯ КОРІНЦЕВИХ ФАЛЬЦІВ КНИЖКОВИХ БЛОКІВ ДИСКОВИМИ НОЖАМИ З ПЛАНЕТАРНИМ ПРИВОДОМ
}

За результатами аналізу встановлено, що міцність незшивного клейового скріплення книжкових блоків залежить від якості обробки корінців та виду клею. Проаналізовано пристрої для зрізування корінцевих фальців книжкових блоків при незшивному клейовому скріпленні. 3 урахуванням проведеного аналізу запропоновано удосконалений пристрій для зрізування корінцевих фальців. Проведено аналітичні розрахунки та побудовано траєкторію руху довільної точки ножа. 3 урахуванням переміщення книжкового блока та траєкторії руху ножа виведено залежність для математичного опису сліду точки ножа на корінці.

Ключові слова: дисковий ніж; книжковий блок; планетарна передача; епіциклоїда; різання; швидкість; привод.

Постановка проблеми

Незшивне клейове скріплення (НКС) книжково-журнальної продукції $€$ домінуючою технологією для виготовлення книг та брошур. Така поширеність обумовлена високою ефективністю процесу, автоматизацією виконання технологічних операцій, а також можливістю вбудовування у високошвидкісні потокові лінії із залученням устаткування для комплектування та обрізування з трьох боків книжкових блоків.

НКС передбачає кількаступеневу обробку корінців книжкових блоків, що, у поєднанні із правиль- ним вибором клею, уможливлює отримання якісного скріплення [1]. Важливою операцією у технологічному ланцюжку обробки корінців є зрізування корінцевих фальців фрезами (торцевими та дисковими), що супроводжується певними недоліками: великими габаритами і споживаною потужністю секції, інтенсивним виділенням паперового пилу та значним шумом. Тому актуальною задачею $€$ роботи направлені на вирішення перелічених недоліків, які становлять інтерес для фахівців відповідної галузі.

() Автор(и) 2021. Видавець КПІ ім. Ігоря Сікорського.

CC BY 4.0 (https://creativecommons.org/licenses/by/4.0/). 


\section{Аналіз попередніх досліджень}

У роботі [2] розглядаються різні аспекти операцій торцевого фрезерування. Ці дослідження доводять виникнення суттєвих навантажень у процесі зрізування корінців книжкових блоків, що призводить до значних енергозатрат.

Автори [3, 4] пропонують для привода дискових різальних інструментів застосовувати кривошипно-кулісний та кривошипно-повзунний механізми відповідно. Очевидно, що наявність циклових механізмів спричинить виникнення значних інерційних навантажень та ускладнить конструкцію вузла загалом.

У роботах авторів [5, 6] розглянуто спосіб обрізування книжкових блоків дисковим ножем, що встановлено з ексцентриситетом. Проведено аналіз дії складових сили різання книжкових блоків. Досліджено траєкторії точок дискового ножа та приклади діаграм для визначення режимів різання. Дані праці доводять перспективи застосування методу різання книжкових блоків ексцентричними дисковими ножами за певних обмежених технологічних умов.

Автори [7] пропонують пристрій для обрізування книжкових блоків набором ексцентрикових дискових інструментів. Однак слід зауважити, що під час різання одночасно набором ексцентрикових ножів виникатимуть короткочасні стрибкоподібні навантаження на привод інструментів.

Застосування дискових ножів відоме й у інших галузях. Зокрема, у роботі [8] досліджено механіку різання дисковим різальним інструментом гірничої породи. У роботі [9] наведено результати експериментальних досліджень різання картону дисковим ножем. В обох випадках авторами отримано важливі результати та моделі поведінки і силового навантаження дискового інструмента в процесі його роботи. Вказані дослідження не спрямовані на різання книжкових блоків та не враховують особливостей паперу в процесі його обробки.

Найбільш наближеним до пропонованого у статті пристрою для зрізування корінцевих фальців € [10]. Однак він має наступні недоліки: наявність двох планетарних передач ускладнює конструкцію різального вузла, збільшує його металомісткість та габарити; застосування додаткової ланцюгової передачі для синхронізації руху обох планетарних передач спричинює додатковий шум; почергове зрізування корінцевих фальців з двох боків книжкового блока призводить до циклічної зміни напружень у ньому, що негативно впливає на якість зрізаної поверхні; відносно велика площа тертя між корінцем та дисковими ножами діаметром

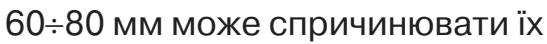
нагрівання, що негативно вплине на якість площини зрізування.

\section{Мета роботи}

Розроблення удосконаленого, порівняно із [10], пристрою для зрізування корінцевих фальців книжкових блоків при НКС, який забезпечить кращі передумови подальшого незшивного клейового скріплення книжковожурнальної продукції. 


\section{Результати проведених досліджень}

З урахуванням переваг та недоліків розглянутих способів та пристроїв у даній роботі пропонується альтернативний пристрій для зрізування корінцевих фальців, права на який захищені патентом України [11].

Пристрій (рис. 1) складається з кареток 1 транспортера із затиснутим книжковим блоком КБ, водила 2, нерухомого зубчастого колеса 3, сателітних зубчастих коліс 4, до осей яких закріплені дискові ножі 5 та нерухомого контрножа 6.

Технологічний процес зрізування корінцевих фальців відбувається наступним чином. Скомплектований книжковий блок КБ товщиною В переміщується з пос- тійною швидкістю $\mathrm{V}_{5}$ каретками 1 транспортера у секцію зрізування корінцевих фальців. Під час транспортування КБ дискові ножі 5, які закріплені до водила 2 по радіусу $R_{\mathrm{B}}$ (водило виконане у вигляді диска), здійснюють складний рух: обертовий з кутовою швидкістю $\omega_{\mathrm{c}}$ навколо власних осей від сателітних коліс 4 та обертовий з кутовою швидкістю $\omega_{\text {В }}$ водилом 2 навколо осі О нерухомо закріпленого зубчастого колеса 3. Зміщення осі обертання водила 2 відносно осі книжкового блока КБ на величину $\mathrm{a}_{\mathrm{w}}$ забезпечує поступове «ковзаюче» різання. Повне зрізування корінцевих фальців здійснюється багаторазовим обертанням водила 2 з сателітними зубчастими колесами 4 та дисковими
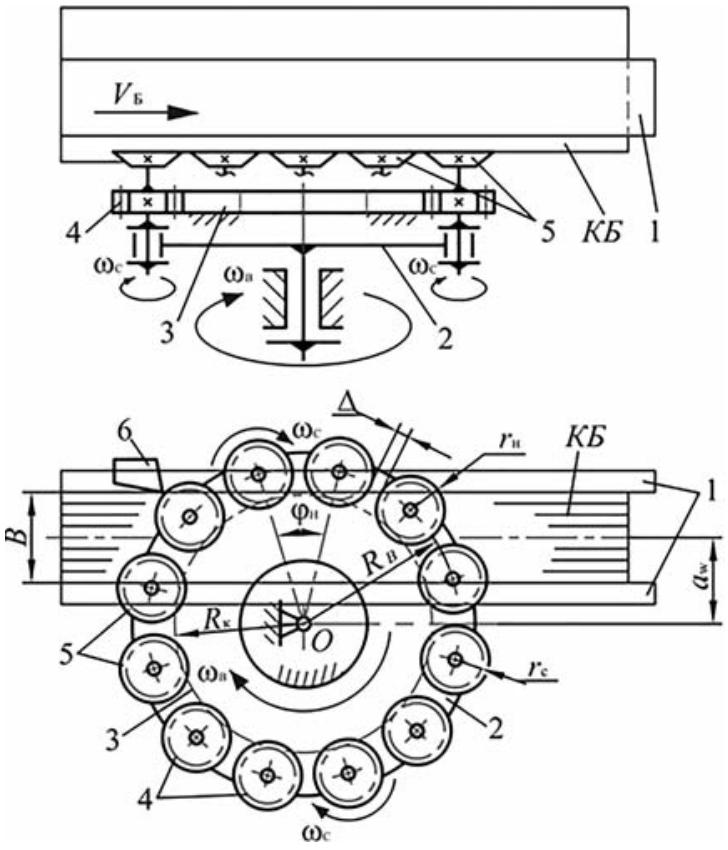

Рис. 1. Принципова схема зрізування корінцевих фальців дисковими ножами з планетарним приводом 
ножами 5 з радіусом $\mathrm{r}_{\mathrm{H}}$. Для надійного дорізування крайніх відносно напряму обертання ножів 5 аркушів книжкового блока КБ застосовується нерухомий контрніж 6.

Таким чином, застосування дискових ножів із планетарним приводом при однобічному зрізуванні корінцевих фальців, порівняно із відомим пристроєм [10], забезпечує наступні переваги: спрощення конструкції, зменшення металомісткості та габаритів, мінімізацію шуму, завдяки відсутності додаткової ланцюгової (зубчастопасової) передачі, зменшення технологічних навантажень, яке спричинене невеликим припуском зрізування одним ножем, покращення якості площини зрізування, що пояснюється відсутністю знакозмінних навантажень, а відтак, періодичному відхиленню корінцевої частини у різні боки відносно його поздовжньої осі.

Кількість z ножів розраховується за формулою $\mathrm{z}=\frac{2 \pi \cdot \mathrm{R}_{\mathrm{B}}}{2 \mathrm{r}_{\mathrm{H}}+\Delta}$. Отримане значення заокруглюється до цілого. Тут $\Delta=5-7$ мм зазор між ножами. Відповідно кут $\varphi_{H}$ між ножами буде дорівнювати: $\varphi_{\mathrm{H}}=360 / \mathrm{z}$.

Траєкторією руху довільної точки ножа при застосуванні планетарного механізму для його привода є епіциклоїда, рівняння якої у параметричній формі [12]:

$$
\begin{aligned}
S_{x}= & r_{C} \cdot(u+1) \cdot \cos \varphi-r_{H} \cdot \\
& \cdot \cos ((u+1) \varphi) . \\
S_{y}= & r_{C} \cdot(u+1) \cdot \sin \varphi-r_{H} \cdot \\
& \cdot \sin ((u+1) \varphi),
\end{aligned}
$$

де $\varphi-$ кут повороту водила, $\mathrm{S}_{\mathrm{x}}$ та $S_{y}$ - відповідно координати переміщення точки ножа вздовж осей Ох та Оу, u $=\mathrm{R}_{\mathrm{K}} / \mathrm{r}_{\mathrm{c}}-$ передатне число планетарної передачі.

У випадку, коли радіус $r_{\mathrm{H}}$ ножа менший від радіуса $r_{c}$ сателітного колеса, отримаємо вкорочену епіциклоїду, при $\mathrm{r}_{\mathrm{H}}>\mathrm{r}_{\mathrm{C}}-$ подовжену. Як приклад, на рис. 2 зображено подовжену $1\left(r_{\mathrm{H}}=30\right.$ мм) та вкорочену 2 ( $r_{\mathrm{H}}=15$ мм) епіциклоїди траєкторії руху довільної точки леза ножа. Розміри передачі приймались із умови встановлення пристрою на виробничій машині, наприклад Trendbinder18 [13] і становили: радіус нерухомого колеса $R_{K}=100$ мм, радіус сателітного колеса $\mathrm{r}_{\mathrm{c}}=20 \mathrm{MM}$, передатне число планетарної передачі $u=5$. При цьому товщина книжкового блока КБ становила В = 40 мм, міжосьова відстань $\mathrm{a}_{\mathrm{w}}=50$ мм, швидкість переміщення книжкових блоків $V_{5}=1,0$ M/c, частота обертання водила $\mathrm{n}_{\mathrm{B}}=200$ об/хв.

За результатами аналізу кривих 1 і 2 можна зробити висновок, що наявність внутрішніх «пелюстків» у подовженої епіциклоїди спричинить додаткове тертя леза ножа по корінцю, що є небажаним. Тому, для подальшого дослідження розглядаємо траєкторію руху довільної точки леза ножа лише для випадку вкороченої епіциклоїди.

Довільна точка леза ножа здійснює складний рух і обертається навколо осі ножа та осі водила. З урахуванням переміщення книжкового блока вона залишить на його корінці слід. На рис. 2 зображено сліди точок (криві 3, 4) двох послідовно розміщених із 


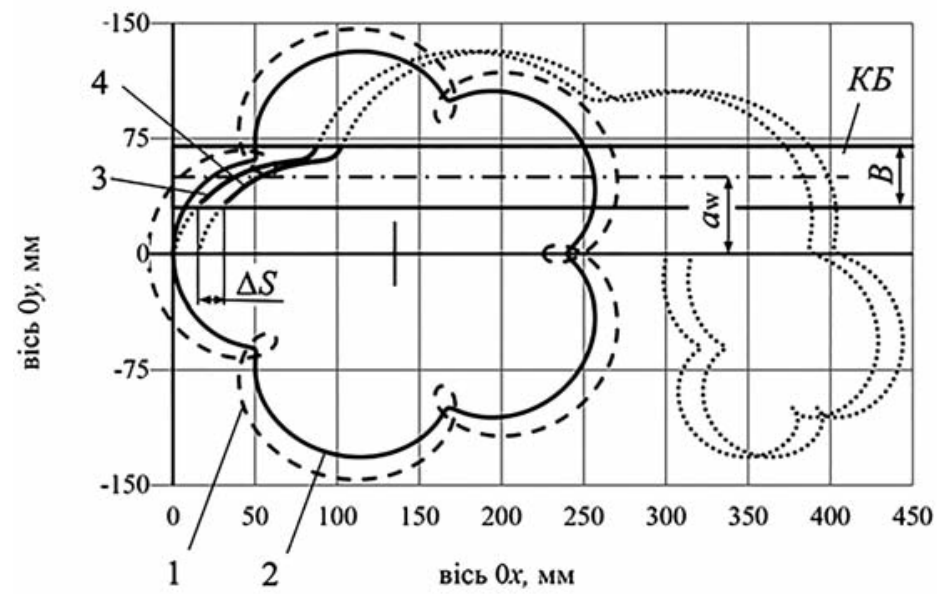

Рис. 2. Траєкторії руху ножа по подовженій (1) та вкороченій (2) епіциклоїді; сліди точок лез на корінці книжкового блока від двох послідовно закріплених на водилі ножів $(3,4)$

зазором $\Delta=7$ мм та кутом $\varphi_{H}=$ $=20^{\circ}$ ножів. Приймали, що кількість ножів рівна $z=18$.

Рівняння сліду кривих 3 і 4 у параметричній формі будуть наступними:

$$
\mathrm{S}_{\mathrm{Cx}}=\mathrm{S}_{\mathrm{x}}+\mathrm{V}_{\mathrm{b}} \cdot \mathrm{t} ; \mathrm{S}_{\mathrm{cy}}=\mathrm{S}_{\mathrm{y}},
$$

де $\mathrm{S}_{\mathrm{cx}}, \mathrm{S}_{\mathrm{cy}}$ - складові переміщення сліду точки леза ножа вздовж осей Ох і Оу, t - поточний час.

Різниця між слідом $\mathrm{S}_{\mathrm{cx} 3}$ i $\mathrm{S}_{\mathrm{cx} 4}$ становитиме припуск $\Delta \mathrm{S}$ (рис. 2), що зрізається одним ножем.

\section{Висновки}

Застосування дискових ножів з планетарним приводом та контрножем для зрізування корінцевих фальців книжкових блоків має ряд переваг над аналогами, головною із яких $€$ «ковзаюче різан- ня». Це створить передумови зменшення технологічних навантажень та потужності привода секції.

За результатами досліджень встановлено характер руху ножа та обґрунтовано доцільність застосування планетарного механізму, що забезпечує траєкторію ножа по вкороченій епіциклоїді. Це забезпечується радіусом сателітного колеса $r_{\mathrm{c}}=20 \mathrm{~mm}$ та дискового ножа $r_{\mathrm{H}}=15 \mathrm{Mm}$.

Виходячи із умови застосування пристрою на виробничій машині запропоновано геометричні розміри планетарної передачі. Зокрема, передатне число повинно становити u $=5$. Для даного випадку побудовано слід точки леза ножа, що враховує його траєкторію та переміщення книжкового блока.

\section{Список використаної літератури}

1. В. Авраменко. Исследование качества клеевого бесшвейного скрепления / В. Авраменко, Э. Галеева // Східно-Європейський журнал передових технологій. 2011. Т. 6. № 4(54). C. 59-62. DOI: 10.15587/17294061.2011.2266. 
2. Протасьев В. Б. Особенности технологии фрезерования корешков бумажных блоков / В. Б. Протасьев, Л. А. Омельченко // Известия ТулГУ. Технические науки. 2012. Вып. 2. С. 442-448. URL: http://tidings.tsu.tula.ru/ tidings/pdf/web/file/tsu izv technical sciences 2012 02.pdf.

3. Іванко А. Пристрій для зрізування корінцевих фальців у книжкових блоках при незшивному клейовому скріпленні / А. Іванко, Д. Гриценко // Комп'ютерні технології друкарства. 2010. № 24. С. 241?247.

4. Іванко А. І. Комбінований привод пристрою для обрізування книжково-журнальних блоків / А. І. Іванко, С. Л. Панов // Технологія і техніка друкарства. 2017. № 2(56). C. 71-76. DOI: https://doi.org/10.20535/20777264.2(56).2017.102044.

5. Яніцкі П. Теоретичні і практичні дослідження обрізування книжкових блоків ексцентричним дисковим ножем / П. Яніцкі // Поліграфія і видавнича справа. 2020. № 2(80). С. 100-111. Режим доступу: http://pvs.uad.Iviv.ua/ uk/articles/theoretical-and-experimental-research-of-book-blocks-cuttingwith-eccetrical-disk-knives/.

6. Яніцкі П. Вплив розташування ексцентричного дискового ножа на сили обрізування книжкових блоків / П. Яніцкі // Наукові записки. 2020. № 2(61). С. 94-102. Режим доступу: http://nz.uad.lviv.ua/uk/articles/influenceof-eccentric-disc-knife-location-on-the-forces-of-book-blocks-cutting/.

7. Коломієць А. Б. Обрізування книжкових блоків набором ексцентрикових дискових інструментів / А. Б. Коломієць, Ю. В. Ватуляк // Поліграфія і видавнича справа. 2020. № 1(79). С. 103-111. Режим доступу: https:// pvs.uad.Iviv.ua/uk/articles/cutting-of-book-blocks-by-a-set-of-eccentricdisc-tools/.

8. Dehkhoda S. Mechanics of Actuated Disc Cutting / S. Dehkhoda, E. Detournay // Rock Mechanics and Rock Engineering. 2017. № 50. pp. 465-483.

9. Rehey I. I. Experimental analysis of corrugated fibreboard cutting with movable cutting disc during large-sized package manufacture / I. I. Rehey, S. V. Ternytskyi, N. M. Kandiak, T. V. Koval // Australian Journal of Mechanical Engineering. 2020. pp. 1-11. http://doi.org/10.1080/14484846.2020.1747734.

10. Іванко А. І. Пристрій для обрізування книжково-журнальної продукції дисковими ножами 3 планетарним приводом / А. І. Іванко // Наукові записки. 2002. № 5. С. 27-30. Режим доступу: http://nz.uad.lviv.ua/uk/articles/prystrii-dlia-obrizuvannia-knyzhkovo-zhurnalnoi-produktsii-dyskovymynozhamy-z-planetarnym-pryvodom/.

11. Патент на корисну модель 127462 Україна, МПК (2006): В42C 5/00, B26D 1/14. Пристрій для зрізування корінцевих фальців книжкових блоків. Книш О. Б., Регей І. І. а201704078. Заявл. 24.04.2017. Опубл. 10.08.2018. Бюл. № 15. 2018. 4 с.

12. Выгодский М. Я. Справочник по высшей математике. 2006. 991 с. Режим доступу: https://msk.edu.ua/s-k/vfn/downloads/1vygodskiy_m_ya_ spravochnik po vysshey matematike.pdf.

13. O. Knysh. Experimental evaluation of the tractive effort of the chain conveyor during book block spine processing by cylindrical milling cutter at perfect binding / O. Knysh, I. Rehei, N. Kandiak, S. Ternytskyi // Acta mechanica et automatica. 2019. vol. 13. no. 2. S. 101-106. DOI 10.2478/ama-2019-0014. 


\section{References}

1. Avramenko, V. \& Galeeva, E. (2011). Issledovanie kachestva kleevogo besshveynogo skrepleniya [Investigation of the Quality of Glued Seamless Bonding]. Skhidno-levropeiskyi zhurnal peredovykh tekhnolohii, Vol. 6, 4(54), 59?62. DOI: 10.15587/1729-4061.2011.2266 [in Russian].

2. Protas'ev, V. B. \& Omel'chenko L. A. (2012). Osobennosti tekhnologii frezerovaniya koreshkov bumazhnykh blokov [Features of the Technology of Milling the Spines of Paper Blocks]. Izvestiya TulGU. Tekhnicheskie nauki, 2, 442-448. Retrieved from http://tidings.tsu.tula.ru/tidings/pdf/web/file/ tsu izv technical sciences 2012 02.pdf [in Russian].

3. Ivanko, A. \& Hrytsenko, D. (2010). Prystrii dlia zrizuvannia korintsevykh faltsiv u knyzhkovykh blokakh pry nezshyvnomu kleiovomu skriplenni [Device for Cutting Root Folds in Book Blocks with Non-Stitched Adhesive Bonding]. Komp'iuterni tekhnolohii drukarstva, 24, 241?247 [in Ukrainian].

4. Ivanko, A. I. \& Panov, S. L. (2017). Kombinovanyi pryvod prystroiu dlia obrizuvannia knyzhkovo-zhurnalnykh blokiv [Combined Drive of the Device for Cutting Book and Magazine Blocks]. Tekhnolohiia i tekhnika drukarstva, 2(56), 71-76. DOI: https://doi.org/10.20535/2077-7264.2(56).2017.102044 [in Ukrainian].

5. Yanitski, P. (2020). Teoretychni i praktychni doslidzhennia obrizuvannia knyzhkovykh blokiv ekstsentrychnym dyskovym nozhem [Theoretical and Practical Research of Cutting Book Blocks with an Eccentric Disc Knife]. Polihrafiia $i$ vydavnycha sprava, 2(80), 100-111. Retrieved from http://pvs. uad.Iviv.ua/uk/articles/theoretical-and-experimental-research-of-bookblocks-cutting-with-eccetrical-disk-knives/ [in Ukrainian].

6. Yanitski, P. (2020). Vplyv roztashuvannia ekstsentrychnoho dyskovoho nozha na syly obrizuvannia knyzhkovykh blokiv [Influence of the Location of an Eccentric Disc Knife on the Cutting Forces of Book Blocks]. Naukovi zapysky, 2(61), 94-102. Retrieved from http://nz.uad.Iviv.ua/uk/articles/influence-ofeccentric-disc-knife-location-on-the-forces-of-book-blocks-cutting/ [in Ukrainian].

7. Kolomiiets, A. B. \& Vatuliak, Yu. V. (2020). Obrizuvannia knyzhkovykh blokiv naborom ekstsentrykovykh dyskovykh instrumentiv [Trimming Book Blocks with a set of Eccentric Disk Tools]. Polihrafiia i vydavnycha sprava, 1(79), 103-111. Retrieved from https://pvs.uad.lviv.ua/uk/articles/cutting-of-bookblocks-by-a-set-of-eccentric-disc-tools/ [in Ukrainian].

8. Dehkhoda, S. \& Detournay, E. (2017). Mechanics of Actuated Disc Cutting. Rock Mechanics and Rock Engineering, 50, 465-483 [in English].

9. Rehey, I. I. \& Ternytskyi, S. V. \& Kandiak, N. M. \& Koval, T. V. (2020). Experimental analysis of corrugated fibreboard cutting with movable cutting disc during large-sized package manufacture. Australian Journal of Mechanical Engineering, 1-11. http://doi.org/10.1080/14484846.2020.1747734 [in English].

10. Ivanko, A. I. (2002). Prystrii dlia obrizuvannia knyzhkovo-zhurnalnoi produktsii dyskovymy nozhamy z planetarnym pryvodom [Device for Trimming Books and Magazines with Disc Knives with Planetary Drive]. Naukovi zapysky, 5, 27-30. Retrieved from http://nz.uad.Iviv.ua/uk/articles/prystrii-dlia-obrizuvannia-knyzhkovo-zhurnalnoi-produktsii-dyskovymy-nozhamy-z-planetarnympryvodom/ [in Ukrainian].

11. Knysh, O. B. \& Rehei, I. I. Prystrii dlia zrizuvannia korintsevykh faltsiv knyzhkovykh blokiv [Device for Cutting Root Folds of Book Blocks] // Patent 127462 UA. Publish 10.08.2018 [in Ukrainian]. 
12. Vygodskiy, M. Ya. (2006). Spravochnik po vysshey matematike [Handbook of Higher Mathematics], 991 p. Retrieved from https://msk.edu.ua/sk/vfn/downloads/1vygodskiy_m_ya_spravochnik_po_vysshey_matematike.pdf [in Russian].

13. Knysh, O. \& Rehei, I. \& Kandiak, N. \& Ternytskyi, S. (2019). Experimental evaluation of the tractive effort of the chain conveyor during book block spine processing by cylindrical milling cutter at perfect binding. Acta mechanica et automatica, vol. 13, no. 2, S. 101-106. DOI 10.2478/ama-2019-0014 [in English].

Due to analysis, the strength of book block perfect binding depends on the quality of its spine processing and adhesive.

The analysis of devices for the back edges cut off from the folded sheets during perfect binding has been performed. Taking into account the analysis, an improved device for back edges cut off from the folded sheets has been proposed. It has been performed analytical calculations and built the trajectory of movement of knife arbitrary point. Considering the book block displacement and the trajectory of knife movement dependency of mathematical description for knifepoint on block spine has been established.

Keywords: disc knife; book block; planetary gear; epicycloid; cutting; velocity; drive. 